\section{Arrebatamento \\ comunicacional pelo \\ sensível e desacontecimento \\ jornalístico}

Tayane Aidar Abib

Mauro Ventura

\section{Resumo:}

Em dialogia com as reflexões de Ciro Marcondes Filho sobre a Nova Teoria da Comunicação, este artigo busca entrecruzamentos teóricos de um tal escopo com a prática jornalística a partir da noção de desacontecimento noticioso. Enquanto estratégia de narração de fatos não-marcados, o desacontecimento dedica interesse a relatos da cotidianidade do homem ordinário, em contraponto aos tradicionais critérios de desvio e proeminência que atravessam a cobertura hegemônica, colhendo das construções de sentidos rotineiras marcas de resistência íntima e social para tessituras intersubjetivas. O presente estudo inscreve, nessa dinâmica, um horizonte possível a uma mediação jornalística sensível e de acolhimento ao Outro, nas trilhas de uma comunicação como fenômeno arrebatador.

Palavras-chave: Nova Teoria da Comunicação. Cotidiano. Desacontecimento.

Communicational rapture by the sensible based on the notion of news as unhappenings

\begin{abstract}
:
In dialogue with Ciro Marcondes Filho's reflections on the New Theory of Communication, this article seeks theoretical intersections of such a scope with journalistic practice from the notion of news "unhappenings". As a narrative strategy for unmarked facts, this notion is interested in reports of the everyday life of the ordinary man, in contrast to the traditional criteria of deviation and prominence that cross the hegemonic news coverage, collecting, from the everyday construction meanings, marks of intimate and social resistance against intersubjective narratives. The present study inscribes, in this dynamic, a possible horizon for sensitive journalistic mediation and welcoming the Other, on the trails of communication as an enthusiastic phenomenon.
\end{abstract}

Keywords: New Theory of Communication. Daily life. "Unhappenings”.
Recebido em: 16.04 .21

Aprovado em: 11.08.21

\section{Tayane Aidar Abib}

Mestre e Doutoranda em Comunicação pela Universidade Estadual Paulista (Unesp). Bolsista da Fundação de Amparo à Pesquisa do Estado de São Paulo (Fapesp).

E-mail: tayaneaabib@ gmail.com

\section{Mauro Ventura}

Professor adjunto do Departamento de Comunicação Social da Universidade Estadual Paulista (Unesp). Livre- Docente em Jornalismo. Doutor em Teoria Literária e Literatura Comparada pela Universidade de São Paulo (USP).

E-mail:msv.ventura@ unesp.br 
ue o jornalismo seja assumido como fenômeno comunicacional, em chave conciliatória com o pensamento propositivo de Ciro Marcondes Filho. É essa a busca central que movimentará nossas incursões neste presente estudo. Interessa-nos desenvolver um atravessamento teórico pelas tessituras do autor brasileiro sobre a Nova Teoria da Comunicação para colher, em suas demarcações epistêmicas acerca do escopo, contribuições para configurar a prática jornalística também em dinâmica de acolhimento, dialogia e arrebatamento intersubjetivo. Especificamente, toca-nos compreender por quais caminhos uma tal articulação pode se fazer possível, cientes de que a relação é sempre um enigma e de que, por isso, não há receita ou protocolo que assegure a eficácia do evento comunicacional. Até porque "a comunicação plena, absoluta, total é impossível" (MARCONDES FILHO, 2008, p. 14).

Um tal reconhecimento não nos impede, no entanto, de inscrever perspectivas de encontro, ou bem vias de acesso, a orientar uma processualidade jornalística mais afeta à partilha do sutil. Alinharemos, neste sentido, comunicação do sensível e mediação jornalística a partir da noção de desacontecimento noticioso, que provoca precisamente a gramática profissionalista hegemônica em suas predileções informativas. Enquanto estratégia de narração de fatos não-marcados, o desacontecimento quer apreender, à parte dos ruídos midiáticos, a cotidianidade do homem ordinário nisso que se mostra criação de sentidos como resistência íntima e social (ESQUIROL, 2015; CERTEAU, 1994). Sua abordagem busca a dinâmica do comum, no compasso dos movimentos rotineiros que significam a existência, individual e coletiva. Em ordem das rupturas, continuidades; em ordem do notável, o anonimato. Pela noticiabilidade do cotidiano, o Desacontecimento se aproxima dos enfrentamentos, cálidos, diminutos e também sempre simbólicos, que cada um realiza para permanecer, intimamente e em convivência social, e que, por relatos tecidos em formas sensíveis, nos pode chegar como toques de epifanização do real.

É no atrito das coisas, diz Ciro Marcondes Filho (2013), "quando algo especial e único atravessa as duas instâncias, na região do contato, área entre um e outro", que a comunicação se realiza, por uma sorte de estalo em que os envolvidos na relação se percebem participando de um mesmo mundo - momento de um intermediário que podemos evidenciar, no jornalismo, seja entre repórter e fonte, seja entre narrativa e leitor. Um horizonte possível, aqui concebemos, quando a dinâmica jornalística elege se situar em esteira dialógico-afetiva, à contrapelo da herança positivista que atravessa o campo (MEDINA, 2008), interessada em abalar a sistemática da noticiabilidade hegemônica, que visibiliza o real por suas dimensões de proeminência social e desvio (SHOEMAKER, 2006; CHARAUDEAU, 2009; SILVA, 2010; SILVA et al., 2014), e de configurar uma semântica informativa a outra, orientada às camadas do ordinário, das resistências e astúcias sutis do que se passa em nossa volta.

Ao se inscrever como ponto de inflexão à processualidade jornalística que historicamente conforma a comunidade profissional (TRAQUINA, 2005; SODRÉ, 2009), o desacontecimento provoca o território da informação a buscar "um além", para nos valermos da expressividade de Marcondes Filho (2019), fundamentado precisamente nas potencialidades intersubjetivas do fenômeno comunicacional e, neste sentido, também associado a um mediador em abertura, que mobiliza, ademais de uma complexa empreitada técnica, concepções éticas e estéticas do fazer. A reestruturação de sentidos que estamos a defender aqui passa, deste modo, também pela práxis consciente de profissionais que articulam ao instrumental aprendido sua intuição afetiva e repertório político-cultural de mundo. 


\section{Comunicação que arrebata}

Uma palavra que parece ser tudo, mas que, do modo como lidamos com ela, não sustenta nada, adverte Ciro Marcondes Filho, lançando a interrogativa que, pelo menos desde o final dos anos 1980, atravessa suas reflexões: "o que vem a ser isso, comunicar?” (2013, p. 9). Nossa inserção em uma sociedade comunicativa é dada como certa, nesta história recente que nos coloca à disposição tantos aparelhos, sistemas, redes e acessos que, nas palavras do pesquisador, mais "nos cegam, nos iludem" (2008, p. 13), que nos aproximam. Colocam-nos em estado de confusão entre emitir mensagens e de fato comunicar. Um risco de tal forma presente que leva o autor a ser referir ao nosso tempo como "o século do paradoxo" (MARCONDES FILHO, 2008, p. 13).

Mesmo quando consideramos o pensamento acadêmico do campo, identificamos o viés funcionalista que continua a orientar nossos estudos: meios, códigos, canais, as técnicas e seus efeitos, as instâncias de emissão e recepção parecem revezar o posto principal de interesse científico quando o assunto é Comunicação. Protagonizam, no decorrer dessa recente história, as discussões de teóricos empenhados em sistematizar suas linhas de ação e identificar seus mecanismos de funcionamento, como se fosse possível reduzir a esquemas um certo tipo de ocorrência que nada tem de material. E longe de descreditar a validade das investigações que nessa linha se desenvolveram, e cuja importância as ciências testemunham, a nossa posição neste artigo enfatiza, fazendo eco ao alerta do sociólogo francês Dominique Wolton (2006, p. 482), a necessidade de se resgatar o valor humanista da Comunicação.

"A comunicação é, pois, ao mesmo tempo desejada e suspeita [...] simboliza de forma bastante clara a ambivalência humana", diz-nos Dominique Wolton (2006, p. 173), como que a indicar, ainda na primeira década do século, aquilo que hoje rotineiramente sentimos, mesmo rodeados de aparatos e tecnologias que facilitam o contato: o aumento do número de mensagens difundidas não encurtou a distância entre transmissão e partilha. Em outras palavras, o progresso técnico não nos aproximou do valor normativo da comunicação, da dimensão da troca, que todos desejamos, mas evitamos pelo receio de correr seus riscos.

O plano técnico, aquele que nos diz das ferramentas e dos mercados, que se materializa pela escrita, a imagem e o som, acaba por obliterar o real sentido do processo, que é nos colocar em relação e em compartilhamento. É nesse sentido que a Comunicação, ao contrário do que intenta mostrar a face da onipotência instrumental, é frágil. Porque nos fala do Outro, e, ao falar do Outro, nos pede respeito e nos pede compreensão. O Outro que, embora mais visível, continua um mistério. Essa alteridade, que hoje pode até nos parecer mais presente, conhecida e fácil de apreender, em verdade continua a revelar que nossas diferenças estão por toda parte.

Comunicar, por isso, é reconhecer o Outro como sujeito, como um alter ego, e isso demanda um movimento profundo de abertura e de escuta. Abundância de troca informativa não é intersubjetividade: cada um reclama seu direito à fala, mas ninguém presta atenção ao outro. "Aquele que deseja ser ouvido está pronto para ouvir? ”, questiona Wolton (2004, p. 80), quando compara o direito à expressão com um monólogo. O que precisamos, adverte o sociólogo francês, é compreender que o fenômeno comunicacional versa, sobretudo, a respeito da possibilidade da escuta. Se a técnica amplia as formas de emissão, há que se aprofundar o debate acerca do retorno. Ou estaremos simplesmente assimilando comunicação à produção e à distribuição de dados.

O receptor não é apenas a outra extremidade de um esquema teórico. É, isso sim, a implicação do que confere à comunicação um estatuto complexo: o horizonte da relação. Reconhecer a reciprocidade como elemento-chave do pro- 
cesso é, então, compreender que a comunicação trata de um encontro com um retorno. É tensão e é risco. É extremamente mais difícil que o contato mediatizado pela técnica, porque é interpelada pelo rosto do Outro. $\mathrm{O}$ rosto que, na filosofia de Emmanuel Levinas (1997, p. 123), desperta-me para a descoberta de uma responsabilidade pelo próximo: "eu me vejo a partir do outro, exponho-me a outrem, tenho contas a prestar".

Coloca-me, assim, a mim mesmo em xeque: quem sou eu e quem, para mim, é o outro? É possível compreendê-lo e é possível que ele me compreenda? As aspirações da comunicação remetem, no fundo, ao fundamento de toda experiência humana - assinalando, por isso mesmo, que há sempre uma possibilidade de fracasso. A proximidade e o confronto que se evitam no plano técnico escapam no encontro cara a cara. A experiência do sentir, o clima, o cheiro, o tato, ameaça-nos justamente porque nos choca com a incerteza.

Longe de uma concepção informacional ancorada na sociologia, portanto, comunicar, de acordo com Muniz Sodré (2014, p. 208), é a ação de, permanentemente, instaurar o comum como vinculação, como um nada constitutivo, "pois o vínculo é sem substância física ou institucional, é pura abertura na linguagem". Inerente à noção de communicatio resgatada pelo autor, assim, está a figura desse sujeito que se comunica que é sempre um ser "entre", ou seja, uma interioridade que se destina a uma exterioridade, que busca o Outro. A existência não é isolamento, em alusão à Jon Patočka (2004, p. 67, tradução nossa), "e bem conduz à comunicação [...], que não é uma transmissão qualquer de um conteúdo qualquer; na comunicação, estamos abertos por inteiro e próximos à alguém”. É uma tal dimensão que possibilita o diálogo e a ação de, a partir da linguagem, abrir-se à transcendência e por em comum as diferenças.

Se compreendemos a Comunicação como essa ação de articulação do comum, então precisamos também considerar que, para além da troca de palavras, há circunstâncias sociais e afetivas que presidem o processo comunicativo, justamente para ampliar e fortalecer o vínculo humano. Partindo do pressuposto de que ela não é uma coisa e de que, como vimos, nada nela se transfere, então não podemos tomá-la como dado fixo e estável. Não podemos olhar para a Comunicação como difusão ou codificação e decodificação de sinais. Antes, e esse é o convite de Marcondes Filho, precisamos concebê-la ultrapassando esse formato e realizando-se no atrito, dos corpos, dos olhares, dos ambientes - e mesmo do silêncio. Acontece, por isso, apenas quando da participação de duas intencionalidades se pode extrair algo novo, inesperado, que modifica o estado anterior de ambos. Há reciprocidade, há manutenção das diferenças individuais - em consonância com Wolton - e, sobretudo, há criação.

No encontro em que sinto efetivamente o outro, eu participo com ele de um momento único, do qual resultam sentidos singulares e exclusivos. Aparte de toda mediatização técnica, a plenitude desse processo somente é possível porque uma relação viva, consigo mesmo e com o outro, revela intimidade, revela corpo, revela gestos, revela comportamentos. Através de nossa expressão, não há como esconder nossos verdadeiros anseios. Estamos diante, assim, de um modelo de comunicação que se situa para muito além das palavras. Mostra-se como um verdadeiro labirinto. Enquanto as palavras são vazias de sentimento e incapazes de traduzir nosso mundo subjetivo, o rosto, novamente ele, "é a superfície porosa que mostra nosso interior, que nos põe a nu" (MARCONDES FILHO, 2004, p. 96). Se na linguagem nós nos disfarçamos e dissimulamos, os olhares e os traços que se desenham em nossa pele deixam escapar os atos puros de uma comunicação real.

Sob essa mirada, a comunicação é um momento, uma ocorrência em que se cria uma situação favorável à recepção do Outro, à recepção do novo. Esse necessário e difícil acontecimento de tornar comum, de "fazer com que uma coisa 
seja a mesma num lado e no outro" (MARCONDES FILHO, 2008, p. 16), é aquilo a que Wolton se refere como dimensão normativa da comunicação. A partilha. E a ela, o estudioso brasileiro acrescenta um caráter único, efêmero e irrepetível. Na contramão da onipresença dos aparatos da informação - do volume crescente de meios, canais e acessos que acabam por nos exaurir, Marcondes Filho coloca o fenômeno da comunicação como processo difícil, designa-o "mágico", porque também composto pelo incorpóreo, e que raramente nos arrebata.

Arrebatamento é a expressão escolhida justamente por indicar um sentido de perturbação: é uma estranheza e um mistério que me desequilibram. Mas me trazem o novo. O Outro, no novo, é que pode me mudar. Ao alterar meus padrões anteriores, ressignifica minha visão das coisas, cria sentido. Enquanto o universo da informação amplia nosso repertório, conformando-nos em território conhecido, aumentando nossas salvaguardas, a comunicação trata de abalos e confrontos. É choque que nos questiona sobre o nosso ser e o nosso estar no mundo: é "afecção que desestabiliza a função cerebral de acoplamento a uma memória anterior, que seria tranquilizante" (MARCONDES FILHO, 2013, p. 23). É, assim, inesperada. Atravessa-nos.

Se tão complexa e nem sempre possível, como viver a ocorrência comunicacional? Em Wolton $(2004,2006)$, encontramos as pistas iniciais no movimento profundo da compreensão e da coabitação das identidades, no voto de confiança a esse Outro que é o nosso alter ego. Em Marcondes Filho (2002, 2004, 2008, 2013), temos a confirmação de que é no diálogo que a comunicação tem a chance de acontecer. Essa acepção busca referências em Maurice Merleau-Ponty, Martin Buber e Emmanuel Levinas para evidenciar que o diálogo é, em verdade, o espaço favorável à emergência de todos os sentidos outrora mencionados: o ambiente comum, a circulação de uma 'extra linguagem', ou os sinais corpóreos que extrapolam nossa fala e, fundamentalmente, é movimento de abertura.

O diálogo pressupõe que os partícipes da relação se esvaziem para acolher o que lhes é dirigido. Nas palavras do filósofo austríaco, identificamos uma espécie de descrição do ato - por ele chamado dialógico, e em Marcondes Filho tido como a possibilidade da mágica da comunicação. "Comunicar efetivamente é sentir junto" (MARCONDES FILHO, 2002, p. 88), ou, poderíamos citar, "na experiência do diálogo, meu pensamento e o seu formam um só tecido" (MERLEAU-PONTY, 2006, p. 474) e, ainda, reforçar, “é o Outro que me arranca da minha hipóstase” (LÉVINAS, 1997, p. 123). Importa-nos, neste contexto, sublinhar que, se o Outro é o estranho mistério que habita em mim, e se o verdadeiro sentido da comunicação é relação e acolhimento, então apenas a abertura para o reconhecimento do Outro enquanto sujeito que comigo experiencia um mundo único, que comigo forma um só tecido, pode fazer chegar a uma comunicação em profundidade, densa e transformadora.

Quando conseguir estabelecer esse pacto com o Outro, nos dizeres de Merleau-Ponty (2006, p. 478), construir um "intermundo no qual dou tanto lugar ao outro quanto a mim mesmo"; quando assumir minha responsabilidade pelo Outro - "estrutura essencial, primeira e fundamental da subjetividade", segundo o filósofo da ética Levinas (1982, p. 88); quando proferir a palavra-princípio Eu-Tu, tomando consciência de que só existo na relação (BUBER, 1979), então estarei vivenciando a passagem da crisálida para a borboleta (MARCONDES FILHO, 2008).

Interessante notar que, ainda que todos os teóricos e estudos até agora articulados empenhem-se em ressaltar a importância da figura do Outro e da esfera da recepção nesse processo, a preocupação que prevalece é a de esmiuçar o agir de um Eu. As ações e posturas que me cabem são com afinco debatidas nessas obras, como que a ecoar, na esteira da ética de Levinas (1982, p. 90, grifos do autor), que a responsabilidade do Outro "é um assunto dele [...] a recíproca é assunto dele". Em alusão à sentença de Fiódor Dostoiévski (2012, p. 396), na obra Os irmãos Karamázov, "somos todos culpados de tudo e de todos perante todos, e eu mais do que 
os outros", Levinas (1982, p. 91, grifo do autor) explicita: "o eu tem sempre uma responsabilidade a mais do que todos os outros".

Ainda que nos escape controlar a simetria da relação - assim o é na filosofia do intelectual francês -, quando falamos de Comunicação, nas condições especificamente favoráveis do diálogo, Marcondes Filho (2013, p. 47) nos recorda que, para sua teoria, importa se ater ao território de interação invisível do "entre", âmbito que engloba o Eu e o Tu, "espaço intermediário, região de contato, área entre um e outro, por onde um elemento incorpóreo, sutil e inesperado anima, vitaliza, energiza". A reciprocidade, para o autor brasileiro, aí acontece como desdobramento natural dos sentidos produzidos pela ocorrência comunicacional. Esse Princípio da Razão Durante pode ser captado pelo que Marcondes Filho denomina de relato metapórico: a descrição do momento genuíno em que, saindo de meu solipsismo, cedo minha própria identidade para que o Outro possa em mim se expandir - sem abdicar de minha subjetividade.

Afim de aproximar tais reflexões ao território das práticas jornalísticas, seguimos adiante nossos entrecruzamentos teóricos a partir da noção de desacontecimento noticioso, enquanto dinâmica que, ao se atravessar por movimentos intersubjetivos para o relato do cotidiano como resistência íntima e social do homem ordinário, é convite ao arrebatamento entre os partícipes da relação jornalística.

\section{Desacontecimento jornalístico}

Em uma primeira aproximação com a noção fundante desses estudos, é importante situar o lugar epistemológico da reflexão sobre o Desacontecimento. $\mathrm{O}$ termo aporta, desde o sentido provocativo de seu prefixo latino, ideias de negação e de oposição para com o escopo que constitui a matéria-prima noticiosa, e conduz o pensamento a ponderar sobre possibilidades de uma feitura informativa outra, à revelia do newsmaking historicamente construído pela comunidade profissional. Seu âmbito investigativo se concentra, por isso, nas Teorias do Jornalismo, especificamente em interface com a perspectiva interacionista e as dinâmicas produtivas que foram conformadas em termos de cultura jornalística, buscando pontos de inflexão para uma processualidade noticiosa divergente. Suas discussões provocam problematizações sobre os fatos reportados pelos meios, em vertente que compreende os saberes mobilizados pelos jornalistas no exercício rotineiro de suas atividades e sua responsabilidade no tecido social.

Enquanto artefato da modernidade, a notícia se estabeleceu na complexa relação entre os pólos econômico e simbólico de um campo em profissionalização (TRAQUINA, 2005; SCHUDSON, 1989; CHALABY, 1998), que por um lado precisava de envergadura comercial para se afirmar como empresa lucrativa, tendo a informação como mercadoria e os leitores como público-consumidor, e por outro almejava assentar sua existência e credibilidade em compasso com valores democráticos, por representações que até hoje pairam sobre o imaginário social, de uma imprensa como porta-voz da opinião pública, defensora da liberdade e da independência e vigia dos poderes instituídos. Neste plano de disputas entre necessidades e interesses da profissão, alojaram-se as competências culturais do jornalismo como comunidade interpretativa (ZELIZER, 2000; PONTE, 2009), no que toca à partilha de convenções perceptivas e avaliativas entre o grupo, para sua lida permanente com um fluxo de ocorrências de difícil controle. Uma sistemática produtiva se constituiu, assim, na esteira dos constrangimentos internos e externos de uma atividade institucionalizada, para orientar uma seletividade noticiosa da cena pública em função de um mapa cognitivo que, conforme estudos da área (PEUCER, 2004; GALTUNG e RUGE, 1965; SHOEMAKER e REESE, 1996; GANS, 2004), privilegia as dimensões de desvio e proeminência social dos fatos. 
A obra de Muniz Sodré (2009, p. 71) é referencial para a compreensão deste processo: diz o autor brasileiro que os profissionais partem do "fato em bruto, ou das qualidades indiferenciadas de um evento, para transformá-lo em 'acontecimento', por meio da interpretação em que implica a 'notícia". O relato noticioso, acrescenta, é o desdobramento ou "a ampliação dos fatos sociais, segundo parâmetros jornalísticos de tratamento que comportam apuração de dados e informações, entrevistas, redação e edição de textos" (idem). Em outras palavras, e para demarcar a acepção elegida nesta pesquisa, a notícia é a construção do acontecimento de acordo com o conjunto de convenções que estruturam o campo jornalístico; uma micronarrativa que resulta da processualidade do fato em acontecimento, no qual o acontecimento se torna esse escopo-central a carregar, em sua configuração, a semântica do exercício de informar.

Desde aí, o ponto chave que se coloca para a reflexão acerca de modos distintos de noticiar, a partir de uma noção de Desacontecimento, é exatamente a interrogante sobre o trabalho de ordenamento de sentidos ao qual se dedica o sujeito-jornalista na relação com o mundo fenomenal. Recapitulando o que Charaudeau (2009, p. 98) denomina de processo evenemencial, consideram-se três instâncias nesta dinâmica de construção: a) há algo que modifica o 'estado normal' das coisas no mundo, b) há um indivíduo dotado de sensibilidade que percebe tal mudança, e c) há a significação que este mesmo sujeito confere a esta mudança, por uma dupla faculdade de "perceber, através de uma experiência direta, aquilo que os fenômenos têm de potencialmente notável, e estruturar o mundo comentando-o com auxílio da linguagem". Cabe evidenciar como a lógica do acontecimento se associa à de impacto sensorial, ou a um caráter de saliência frente à aparente uniformidade em que se vive (RODRIGUES, 1999; MARTINI, 2000), e como, assim operando, descarta os aspectos de regularidade e permanência que também envolvem a narrativa social.

Nesta linha, Márcia Benetti (2004) adverte para os riscos de silenciamento que, desde a compreensão do jornalismo como acontecimento, reside nas angulações e vozes que ele marginaliza, por um regime discursivo que acaba por gerar, indiretamente, um senso de conformismo coletivo. Resulta inevitável depreender que, enquanto uma escolha, o acontecimento-notícia é também uma omissão. "Toda forma de ver é uma forma de ocultar”, pontua Alsina (2005, p. 127, tradução nossa), e é precisamente as camadas de vida e mundo desprezados, ou deixados à sombra, pelo recorte jornalístico que movimentam nossa postura investigativa. Pelo escopo do Desacontecimento, tem sido possível tratar de possibilidades de contraposição ao trabalho de significação dos meios hegemônicos, através de uma ênfase a estratégias de narração orientadas aos fatos não-marcados pelo tinteiro dos critérios convencionais, centrados naquelas dimensões rasamente percebidas como ordinárias ou comuns.

Ainda que fatores ideológicos, políticos e culturais atravessem a processualidade da notícia (SOLOSKI, 1999; HALL, 1999; GOMES, 2009), em determinados contextos até de modo impeditivo, o Desacontecimento enquanto prática à revelia implica mais diretamente o sujeito-jornalista e seu ambiente redacional. Envolve um como os repórteres se apropriam do quadro de sentidos vigentes ao seu exercício de trabalho, e da própria cultura profissional que lhes rodeia, quer dizer, se administram ou se renovam as convenções. A assinatura criativa do fazer demanda movimentos de resistência em relação aos padrões estabelecidos, tanto para as figuras que lidam imediatamente com a pauta, a partir de suas escolhas narrativas, quanto para os agentes de editoria, que podem fazer frente a essa dinamicidade na busca por brechas informativas. A complexidade de sua equação considera as aportações biográficas, coletivas e profissionais dos atores que a engendram e se favorece em entornos organizacionais que apostam na autonomia das mediações, pela percepção dessas controvérsias de luz e sombras, ou de ruídos e silêncios, que conjugam o real midiático (KÜNSCH, 2005; MEDINA 2006, 2016). 
A matéria-prima noticiosa se compreende, tal qual outrora situado, como constructo profissional (ROSHCO, 1975; TUCHMAN, 1978) que, em correspondência a demandas organizacionais e expectativas públicas, privilegia um modo de perceber e conhecer a história através de seus aspectos irruptivos ou de associação a figuras de poder. O Desacontecimento, ao questionar a marcação dos fatos que logram a agenda midiática, e pública, abala a sistemática da noticiabilidade hegemônica e estabelece um domínio de discordância, de insatisfação entre sua pauta e os critérios tradicionalmente elegidos pela instância produtiva para reportar as ocorrências. Configura uma cena cognitiva outra, à sombra da desordem aparente, e que se dispõe pela rítmica do espaço-tempo vivido. Insere-se nas margens negligenciadas de protagonismo coletivo e informativo, pelas camadas secundárias dos fenômenos sociais, assim centrando predileção noticiosa à cotidianidade do homem ordinário.

Com isso, quer-se dizer que a abordagem do Desacontecimento busca a dinâmica do comum, no compasso dos movimentos rotineiros que significam a existência, individual e coletiva. A cotidianidade se inscreve, pela mirada do Desacontecimento, como território por excelência para as coberturas informativas, desde seus rearranjos em chave de criação e recriação de sentidos. Aqui, duas perspectivas teóricas, a partir de Josep Maria Esquirol $(2009,2015)$ e Michel de Certeau (1994, 1996), contribuem, em plano dialógico, para uma tal compreensão: o filósofo catalão por sua ênfase às recorrências dos dias enquanto resistência íntima, e o historiador francês, por sua percepção do ordinário, como prática do singular insinuada por astúcias e táticas sutis.

As repetições cotidianas, sob o prisma do filósofo catalão, não são apenas reminiscências ou monotonias; são movimentos adiante, que no compasso do retorno nos abrem o possível futuro, e que na oportunidade do agora nos firmam, cada vez mais intimamente, o lugar das coisas que importam - "repetição cordial e voltada ao coração", escreve (ESQUIROL, 2009, p. 176). Essa 'roda' diária, por isso, é também hábito: uma maneira continuada ou regular de se fazer próprio, não como uma posse e sim como uma forma de ser, que se associa à ideia de 'habitação', um ambiente que nos é familiar. Desde aí, a cotidianidade é o que torna a vida um abrigo, que nos mantém aquecidos e seguros frente a intempéries diversas justamente porque, em partitura de previsão e de reinício, nos entrega um ritmo orientador de vida. Não à toa, Esquirol se refere à rotina como musicalidade dos dias: podemos achar que sabemos de cor sua composição, mas a experimentaremos de um jeito sempre muito nosso, nunca idêntico, com o conforto de quem se reconhece em território seguro, e na intensidade de ser atravessado por sensações sempre novas.

A cotidianidade que nos serve à incursão de uma ontologia originária é, deste modo, a mesma que nos estabelece como sujeito-protagonista de produção de sentidos. Esse tal mecanismo das criações, por muitas vezes minúsculas, já que nos espaços de nossa intimidade, nos realça ou, para valer-se de um termo acionado por Maffesoli (1996), “epifanizam” o real. Na dimensão do cotidiano que, para o sociólogo francês, nos aparece como 'centralidade subterrânea', a marca distintiva se encontra em um querer viver irreprimível, cuja força ganha forma por uma criatividade intuitiva a que Cremilda Medina (2014, p. 83), em um neologismo muito à brasileira, chama de sevirol - "o verdadeiro milagre da vida apesar de tudo". Em foco, está uma espécie de capacidade de sobrevivência do humano ser na inventividade, suas 'virações' para lidar com a dinâmica vivida, cujo domínio expressivo não pode ser outro que o espaço-tempo diário. Os pequenos fatos da vida cotidiana carregam o fundamento incontornável de nossas maneiras de ser, o sentimento de vida que, em aparente simplicidade, tensiona o nosso aqui e agora com os outros, nas contradições mesmo de um fervilhar existencial.

E isso também em esfera social. Na obra de Certeau (1996), temos a preocupação por uma distinção entre ordinário e massivo justamente para demarcar que, 
se a segunda simplifica os modelos culturais para ampliar sua difusão, a noção do ordinário salienta um trato com o entorno em função de códigos particulares, como uma "ciência prática do singular [...] que seleciona seus próprios instrumentos de pensamento e suas técnicas de uso em vista desses critérios" (CERTEAU, 1996, p. 341). O interesse do historiador francês em aprofundar uma reflexão sobre cultura ordinária é fundamentar a assertiva de que, a despeito das determinações e ordens de estrutura que tentam se impor, insinua um "estilo de trocas sociais", ou de invenções técnicas de resistência moral.

Em outros escritos, Certeau (1994, p. 20) já se referiu aos qualificativos da dinâmica cotidiana como "'uma economia do dom', 'uma estética de lances' e uma 'ética da tenacidade"”, explicitando as combinatórias de operações que o sujeito, para subverter o estatuto de dominado, lança mão em suas "mil maneiras de caça não autorizada" (CERTEAU, 1994, p. 38). Sua linha interpretativa não nos deixa esquecer de que o cotidiano é também espaço de embates e negociações, onde há fabrico ou poética, que se inventa apesar das sistemáticas comerciais, urbanas e midiáticas.

Vê-se como no pensamento do autor, assim, nós encontramos referência ao dia-a-dia como o que nos cabe em partilha, como o que nos prende intimamente ou o "mundo que amamos profundamente, memória olfativa, memória dos lugares da infância, memórias do corpo, dos prazeres" (CERTEAU, 1996, p. 31), mas é, sobretudo, pela inserção de um tal território como caminho na resistência do sistema social, "com operações quase invisíveis e quase inomináveis" (CERTEAU, 1996, p. 340), que sua contribuição é aqui acionada. Porque, ademais de uma proposição que considera as potências de negociação dos rotulados como dominados, no plano mesmo de suas vivências rotineiras, há um aspecto ético ligado à cotidianidade que nos é caro frisar: a defesa de uma autonomia de algo próprio, ou de um gesto de poética capaz de reempregos transformantes.

Destaca-se, por isso, que a regularidade que, à primeira vista, é repetição inócua da leva dos dias, ao Desacontecimento é o fluxo sempre adiante, de homens e mulheres comuns, na lida possível com a realidade que lhes chega. Sob esta posição propositiva, o Desacontecimento não se aparta das ocorrências generalistas da vida local, nacional e internacional, mas demarca, antes, a cotidianidade como locus favorável para uma abordagem jornalística interessada em apreender a dimensão do ordinário, das resistências e astúcias sutis que atravessam as relações humanas e os entornos.

\section{Em vias sensíveis}

A orientação da atenção ao plano da cotidianidade, não obstante, também depende da mobilização de um aparato sensível em termos de apuração e escuta desses sentidos. Se nos toca pensar em arrebatamento comunicacional e mediação jornalística, nos horizontes possíveis para se alcançar "o jornalismo que mexe com a gente" (MARCONDES FILHO, 2008, p. 158), então vale situarmos a "importância capital no processo comunicacional [...] de situações particulares de afeto, de abertura e dedicação" (p. 152) - da figura de um repórter, aqui inscrevemos, que faz de seu exercício um convite ao mundo partilhado. Que aciona o desacontecimento como uma matriz viável para acolher o Outro em seus minúsculos de resistência íntima e social e para, desde essa alteridade, estabelecer também com o público uma dialogia.

Neste sentido, cabe-nos um último apontamento, que embora provenha de uma reflexão não diretamente ligada à epistemologia da comunicação, bem pode nos ajudar a inscrever demarcações acerca do ethos mobilizado por essa guinada intersubjetiva - o qual, logicamente, não tem nenhuma pretensão de limitar ou engessar a ocorrência comunicacional. À uma dinâmica configurada em plano sensível, afinal, deve corresponder um sujeito que se reveste por igual sensibilida- 
de, uma maneira de ser mais afetiva e reflexiva, que Josep Maria Esquirol (2018) expressa pelo termo catalão replec del sentir.

A proposta que o filósofo lança em tom ensaístico é o cerne de seu mais recente livro La penúltima bondad, e aporta a noção de que nossa essência é afetiva, não em termos de uma acuidade, mas de vulnerabilidade e capacidade de receber e ser ferido. Aqui, percebemos a inspiração levinasiana que conflui com o pensamento de Esquirol (2018, p. 26, tradução nossa), a projetar o estado de ânimo originário do homem como abertura do sentir, a que ele enfatiza: o princípio não é apenas o sentimento, mas o sentir que sentimos. "A declaração mais séria em três palavras: 'Eu sinto que sinto'. Eu sinto tudo que faço e tudo o que se passa comigo", isto é, não apenas vivo, mas me sinto vivo, em uma relação direta do viver comigo, mas que não se esgota aí. Há também uma relação reflexiva de mim mesmo comigo: sinto que me sinto vivo. Nisto consiste a ideia de um replec, que poderíamos traduzir como uma modalidade de sentir de uma tal intensidade que faz um trajeto de retorno, ou dobra, volta-se para si mesma.

Se imaginarmos o sentir como uma função que cresce, podemos considerar que, em determinado ponto, a função atingiu tanto que desce e se dobra, ou seja, se dobra sobre si mesma. A linha da passividade-sensibilidade dobrou-se sobre si mesma e deixou um pequeno espaço no meio [...]. O retorno do sentir não só acarreta mais afecção, mas uma espécie de afecção da afecção; e afeto profundo, afeto que toca o coração (ESQUIROL, 2018, p. 36, tradução nossa).

O sentir, assim, desde a visada empreendida pelo autor catalão, abarca da percepção e da realização sensível ao próprio pensamento, como uma sorte de clarividência de auto percepção e de autoconhecimento sobre nossas experiências, que embora pareça simplesmente involuntário, uma vez que nos constitui, atrela-se a um necessário movimento de despertar - de receber e responder às três afecções mais nucleares e penetrantes: a vida, enquanto singularidade em um tempo finito; o Outro, como experimento de alteridade fundante; e o mundo, como horizonte que integra nossas relações e espaço que nos cabe apreender e transformar. O pensar, vinculado a essas irradiações, nada mais faz que conferir maior concretude aos nossos esforços para abordar e tentar tocar as sensações que nos chegam.

Uma aproximação entre tal pensamento e a Comunicação, que é sempre de uma ordem penúltima, porque o "sentir-se vivo não captura nenhum fim que possa completá-lo" (ESQUIROL, 2018, p. 157, tradução nossa), ensaia as potências de uma prática intersubjetiva que não se pode dissociar de um sujeito disposto a arriscar-se nas tessituras dos afetos. Um mediador em abertura, tal qual também aborda Moraes (2019), que se reconhece implicado com os universos que reporta e que se quer à flor da pele, como popularmente costumamos dizer, para conviver com a vitalidade densa e tensa que a todo momento se lhe revela.

\section{Considerações finais}

As reflexões de Ciro Marcondes Filho acerca da Comunicação assumem, nessas páginas, um contorno de provocação: pode o jornalismo também se configurar no plano do sensível, enquanto fenômeno capaz de arrebatar os partícipes nela envolvidos - repórter e fonte, em nível mais direto, e narrativa e leitor, em escala de difícil ponderação, porém parte desse horizonte relacional? Os desdobramentos de uma tal empreitada se fazem, aqui, por entrecruzamentos teóricos que, sob a noção do Desacontecimento, buscam convergir para uma dinâmica jornalística mais intersubjetiva em seus processos, desde o interesse informativo pelo cotidiano de resistências, íntima e social, do homem ordinário.

A matéria-prima noticiosa, conforme assinalamos neste texto, privilegia um certo modo de perceber e conhecer a história através de seus aspectos irruptivos 
ou de associação a figuras de poder. Da primeira tese de jornalismo apresentada em universidade, por Tobias Peucer (2004), às sistematizações dos valores-notícia por Galtung e Ruge (1965), Mauro Wolf (2003), Nelson Traquina (2005), entre outros teóricos, a seletividade informativa aponta para uma marcação hegemônica dos fatos por sua dimensão de desvio. Se a cobertura dos grandes meios nos satura com o barulho do signo, "em que só se presta atenção àquilo que é gritado, berrado, vociferado na publicidade, na TV, no cinema", Marcondes Filho (2019, p. 137) coloca a comunicação do sensível em "contracorrente ao chamado 'totalitarismo da sensibilidade' [...] totalitarismo indecente que se contrapõe aos microacontecimentos da vida cotidiana".

Os próprios escritos do autor, assim, nos dão pistas para buscar o sutil tão almejado na comunicação em vias de um (re)encantamento - para nós, em termos jornalísticos - com a polissemia das pequenas coisas, o desacontecer da vida comum, em suas permanências rotineiras ante a intempéries diversas. Um tal movimento, conforme evidenciamos, realiza-se pela mediação de um sujeito que, nas trilhas da autoria de que fala Medina (2014), enseja um fazer dialógico, de partilha em alteridade com o Outro e replec de sentir que lhe abre os poros para uma sintonia vívida com o mundo.

E como "a comunicação é uma ocorrência incerta entre pessoas ou entre pessoas e aparelhos" (MARCONDES FILHO, 2019, p. 11), bem cabe considerar as incursões aqui desenvolvidas como um convite, ou um caminho possível a esses encontros, raros, difíceis e necessários, no jornalismo.

\section{Referências}

BENETTI, M. O jornalismo como acontecimento. In: VII Encontro Nacional de Pesquisadores em Jornalismo (SBPJor). Anais... São Paulo: USP, 2004.

BENETTI, M; FONSECA, V. Jornalismo e Acontecimento: mapeamentos críticos. Florianópolis: Insular, 2010.

BUBER, M. Do diálogo e do dialógico. São Paulo: Perspectiva, 1982.

BUBER, M. Eu e tu. 2a edição revista. São Paulo: Cortez \& Moraes, 1979.

CHALABY, J. The invention of journalism. London: MacMillan Press, 1998.

CHARAUDEAU, P. Discurso das mídias. São Paulo: Contexto, 2009.

CERTEAU, M. A invenção do cotidiano: artes de fazer. Petrópolis: Vozes, 1994.

CERTEAU, M.; GIARD, L.; MAYOL, P. A invenção do cotidiano 2: morar, cozinhar. Petrópolis: Vozes, 1996.

DOSTOIEVSKI, F. Os irmãos Karamázov. São Paulo: editora 34, 2012.

ESQUIROL, J. El respirar de los días. Barcelona: Paidós, 2009.

ESQUIROL, J. La resistencia íntima: ensayo de una filosofía de la proximidad. Barcelona: Acantilado, 2015.

ESQUIROL, J. La penúltima bondat: assaig sobre la vida humana. Barcelona: Quaderns Crema, 2018. 
GALTUNG, J.; RUGE, M. The structure of foreign news. Journal of Peace Research, v.2, n.1, p.64-91, 1965.

GANS, H. Deciding what is news. Evanston, IL: Northwestern University Press, 2004.

GOMES, W. Jornalismo, fatos e interesses: ensaios de teoria do jornalismo. Florianópolis, Insular/POSJOR-UFSC, 2009.

HALL, S. et al. A produção social das notícias: o mugging nos media. In: TRAQUINA, N. (org.). Jornalismo: questões, teorias e 'estórias'. Lisboa: Vega, 1999.

KÜNSCH, D. Maus pensamentos: os mistérios do mundo e a reportagem jornalística. São Paulo: Annablume: FAPESP, 2005.

LÉVINAS, E. Humanismo de outro homem. Petrópolis, RJ. Vozes, 1993.

LÉVINAS, E. Entre nós: ensaios sobre a alteridade. Petrópolis: Vozes, 1997.

LÉVINAS, E. Ética e infinito. Lisboa: Edições 70, 1982.

MAFFESOLI, M. No fundo das aparências. Petrópolis: Vozes, 1996.

MARCONDES FILHO, C. O rosto e a máquina: o fenômeno da comunicação visto pelos ângulos humano, medial e tecnológico. São Paulo: Paulus, 2013.

MARCONDES FILHO, C. Para entender a comunicação: conceitos antecipados com a nova teoria. São Paulo: Paulus, 2008.

MARCONDES FILHO, C. Comunicação do sensível. São Paulo: ECA/USP, 2019.

MARCONDES FILHO, C. O espelho e a máscara: o enigma da comunicação no caminho do meio. São Paulo: Discurso Editorial; Ijuí: Unijuí, 2002.

MARCONDES FILHO, C. O escavador de silêncios: formas de construir e desconstruir sentidos na comunicação. São Paulo: Paulus, 2004.

MARCONDES FILHO, C. Para entender a comunicação: conceitos antecipados com a nova teoria. São Paulo: Paulus, 2008.

MARTINI, S. Periodismo, noticia y noticiabilidad. Buenos Aires: Editorial Norma, 2000

MEDINA, C. O signo da relação: comunicação e pedagogia dos afetos. São Paulo: Paulus, 2006.

MEDINA, C. Ciência e jornalismo: da herança positivista ao diálogo dos afetos. São Paulo: Summus, 2008.

MEDINA, C. Atravessagem: reflexos e reflexões na memória de repórter. São Paulo: Summus, 2014.

MERLEAU-PONTY, M. Fenomenologia da percepção. São Paulo: Martins Fontes, 2006. 
MORAES, F. Subjetividade: Ferramenta para um jornalismo mais íntegro e integral. Extraprensa, São Paulo, v. 12, n. 2, p. 204 - 219, jan./jun. 2019.

PATOCKA, J. El movimiento de la existencia humana. Encuentro, 2004.

PEUCER, T. Os relatos jornalísticos. Revista Estudos em Jornalismo e Mídia, v.1, n.2, p.13-29, 2004.

PONTE, C. Os jornalistas como "comunidade interpretativa transnacional". Estudos em Jornalismo e Mídia (Florianópolis), v. 6, n.1, 2009.

RODRIGUES, A. O acontecimento. In: TRAQUINA, Nelson (Org). Jornalismo: questões, teorias e “estórias”. Lisboa: Vega, 1999.

ROSHCO, B. Newsmaking. Chicago: The University of Chicago Press, 1975.

SCHUDSON, M. The socology of news production. Media, Culture, and Society. v.11, n.3, p.263-282, 1989.

SHOEMAKER, P. News and newsworthiness: a commentary. Communications, v.31, p.105-111, 2006.

SILVA, G.; SILVA, M.; FERNANDES, M. (Orgs). Critérios de noticiabilidade: problemas conceituais e aplicações. Florianópolis: Insular, 2014.

SILVA, M. As dissonâncias cotidianas nas rotinas dos jornais. Estudos em Jornalismo e Mídia, v.7, n.1, p.69-84, jan/jun. 2010.

SILVA, M. Como os acontecimentos se tornam notícia. Estudos em Jornalismo e Mídia, v.10, n.1, p.173-184, jan/jun. 2013.

SODRÉ, M. A narração do fato: notas para uma teoria do acontecimento. Petrópolis: Vozes, 2009.

SODRÉ, M. A ciência do comum: notas para o método comunicacional. Petrópolis: Vozes, 2014.

TRAQUINA, N. Teorias do jornalismo: a tribo jornalística - uma comunidade interpretativa transnacional. Vol. 2. Florianópolis: Insular, 2005.

TUCHMAN, G. Making news: a study in the construction of the reality. New York, The Free Press, 1978.

WOLF, M. Teorias da Comunicação. São Paulo: Martins Fontes, 2003.

WOLTON, D. É preciso salvar a comunicação. São Paulo: Paulus, 2006.

WOLTON, D. Pensar a comunicação. Brasília: Ed. Da UnB, 2004.

ZELIZER, B. Os jornalistas enquanto comunidade interpretativa. In: TRAQUINA, N. (Org.). Jornalismo 2000. Lisboa: Relógio d'água, 2000. 